\title{
Dietary lipids, platelet function and arterial thrombosis in animals and man
}

\author{
By Gerard Hornstra, Department of Biochemistry, Limburg University, PO \\ Box 616, 6200 MD Maastricht, The Netherlands
}

It is now generally accepted that the type and amount of dietary fat can affect the genesis and course of experimental atherosclerosis (Vles et al. 1964; Kritchevsky, 1969; Malmros, 1969; Wissler \& Vesselinovitch, 1975; Weber, 1978). Moreover, epidemiological studies clearly indicate that the type of dietary fat has a distinct influence on coronary artery disease (CAD) which is one of the clinical manifestations of atherosclerosis (Kannel, 1970; Stamler, 1973; Heyden, 1975; Renaud et al. 1979; Kronmann \& Green, I980). Human prospective studies also show that diets low in long-chain saturated fatty acids and enriched with linoleic acid are beneficial to CAD-prevention (Turpeinen, 1968; Dayton et al. 1969; Leren, 1970; Miettinen et al. 1972). Since blood platelets are instrumental in arterial thrombosis, and arterial thrombosis is implicated in atherosclerosis and its complications (Chandler, 1982), the dietary fat effect on atherogenesis may, at least in part, be mediated by the influence on platelet function and arterial thrombosis.

\section{Effect of type of dietary fat on arterial thrombosis in a rat model}

Arterial thrombosis tendency was measured in rats, using a newly-developed model (Hornstra \& Vendelmans-Starrenburg, 1973) which is based on the introduction of a loop-shaped polyethylene cannula into the abdominal aorta of male animals. Endothelial damage and flow disturbances cause the formation and growth of a platelet-rich, fibrin-poor mural thrombus, the structure of which is similar, in comparative phases of development, to that of natural arterial thrombi in man. The thrombus reaches an occlusive state after about $5 \mathrm{~d}$. The moment of obstruction is indicated by a change in colour of the blood from light-red to dark blue. This can easily be observed, since the loop is made of translucent material and partly protrudes from the body. The period between insertion and complete obstruction of the loop is called the obstruction time (OT) and is a measure of the arterial thrombosis tendency of the animal: the longer the OT, the lower the thrombosis tendency. The usefulness of the aorta-loop technique was demonstrated by the observation that compounds influencing platelet aggregation and blood coagulation affect the arterial thrombosis tendency in a predictable manner. Moreover, known risk factors for atherosclerosis and thrombosis were shown to be associated with decreased obstruction times (Hornstra, r 980).

To study the effects of dietary fat on this model, 3-5-week-old male rats were given adequate diets, the carbohydrate moiety of which was isoenergetically replaced by various amounts of different oils and fats. Aorta-loops were inserted after 8-12 weeks. In a first series of experiments (Hornstra, 1971), it appeared that 
sunflower-seed oil, and its linoleic acid fraction in particular, lowered the arterial thrombosis tendency in a dose-dependent manner. In a further series of experiments (Hornstra \& Lussenburg, 1975), the anti-thrombotic effect of linoleic acid was confirmed. Moreover, it was demonstrated that long-chain saturated fatty acids containing fourteen or more carbon atoms increase the arterial thrombosis tendency in a dose-dependent manner. Palm oil did not fit this relationship: although it contains almost $50 \%$ palmitic and stearic acids, it lowered the thrombosis tendency.

The fact that only long-chain saturated fatty acids are thrombogenic, implies that their replacement with unsaturated fatty acids will decrease thrombogenicity. To establish whether unsaturated fatty acids differ as to this 'passive' antithrombotic effect, the two most common, oleic acid (18:1 109$)$ and linoleic acid

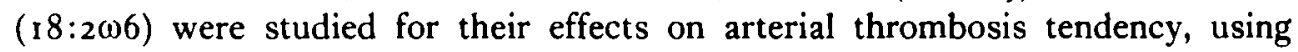
special fat mixtures containing various amounts of hydrogenated palm oil (mainly palmitic and stearic acid), olive oil (mainly oleic acid), and safflower-seed oil (mainly linoleic acid). From the results (Fig. I) it appeared that for each of the two saturated fat levels, the OT is longer (so thrombosis tendency is lower) in the group receiving the diet high in linoleic acid and low in oleic acid. These results demonstrate that linoleic acid, apart from its 'passive' antithrombotic effect when replacing long-chain saturated fatty acids, also has an 'active' antithrombotic effect.

From studies with hydrogenated soya-bean oil containing almost $60 \%$ trans-isomers of oleic and linoleic acids, as well as from a direct comparison

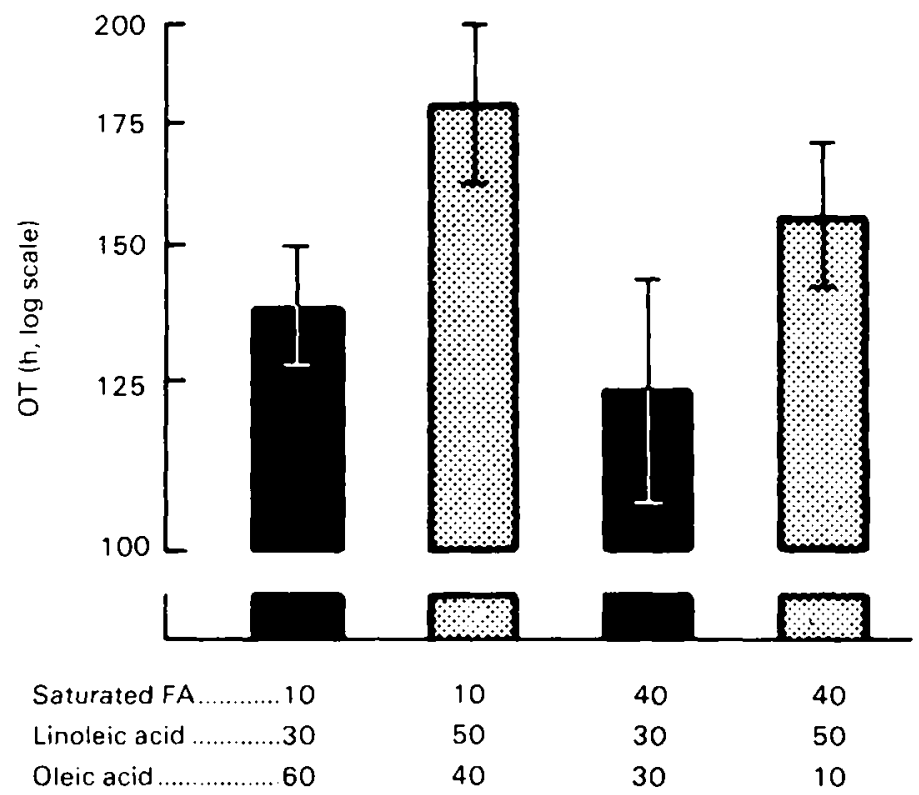

Fig. 1. Effect of dietary fatty acid (FA) composition ( $\%$ ) on obstruction times (OT, h; log scale) of aortic loops in rats. Diets contained $50 \%$ of the digestible energy as fat. Values are means with their standard errors, represented by vertical bars, for twelve rats per group. 
between cis- and trans-oleic acid, it appeared that there is no difference between the antithrombotic effect of cis- and trans-unsaturated fatty acids (Hornstra, 1982).

In the studies described so far, whale oil appeared to be one of the most thrombogenic oils. This is not in agreement with recent ideas as to the possible beneficial effects of fish and other marine products. These ideas are based on short-term feeding studies following epidemiological observations that mortality from acute myocardial infarction is very low in Greenland Eskimos, living traditionally (Kronmann \& Green, I980). This has been attributed to their high intake of timnodonic acid $\left(20: 5 \omega_{3}\right)$ which has been shown to lower blood lipids (Bang et al. 1971) and which is claimed to shift the balance between the formation of prothrombotic thromboxane in platelets and the antithrombotic prostacyclin by the vessel wall towards a less thrombogenic state (Dyerberg et al. 1978).

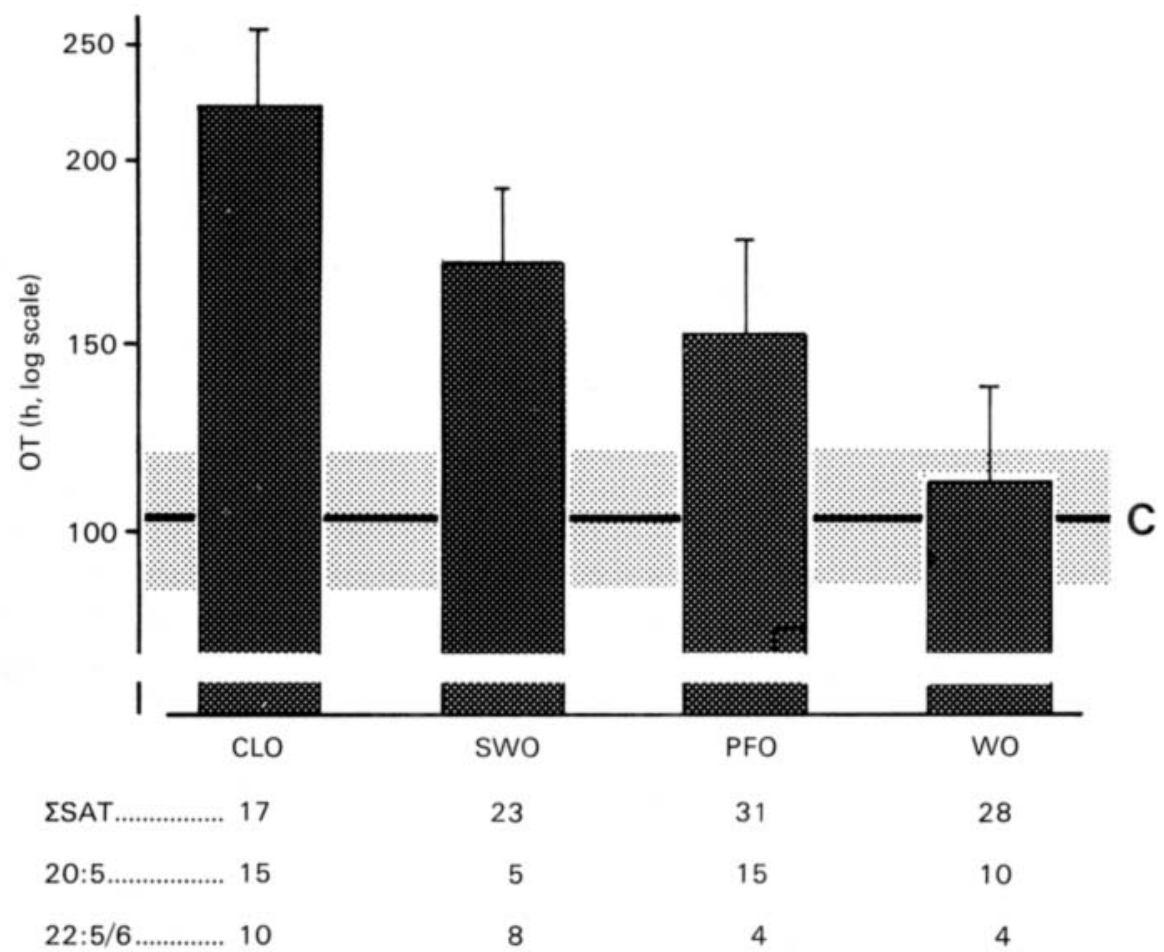

Fig. 2. Effect of various marine oils $(45 \%$ of digestible energy $+5 \%$ of digestible energy as sunflower-seed oil to prevent essential fatty acid deficiency) on obstruction times (OT, h; log scale) of aortic loops in rats. Values are means with their standard errors represented by vertical bars. CLO, cod-liver oil $\left(P_{2}=0.004\right)$; SWO, sperm-whale oil $\left(P_{2}=0.02\right)$; PFO, Peruvian fish oils (NS): WO, whale oil (NS); $C$, control diet, containing $5 \%$ of digestible energy as sunflower-seed oil; ISAT, total amount $(\because)$ of long-chain saturated fatty acids in marine oils; $20: 5$, content $(\mathcal{F}$ ) of timnodonic acid $\left(20: 5 \omega_{3}\right) ; 22: 5 / 6$, total amount $(?)$ of $22: 5 \omega_{3}+22: 6 \omega_{3} ; P_{3}$, probability of difference as compared with control dict (Student's two-sample test); NS, not significant $P_{2}>0$ 05). 
However, it should be noted that the traditional Eskimo diet is also characterized by a low content of long-chain saturated fatty acids (Bang et al. r 980 ), whereas the whale oil used in our study contained appreciable amounts of palmitic and stearic acids. Therefore, we compared various marine oils for their effect on arterial thrombosis tendency in the rat. It then appeared (Fig. 2) that thrombogenicity is predicted best by the ratio, long-chain saturated fatty acids: sum of timnodonic acid and the other long-chain polyunsaturated fatty acids of the $\omega_{3}$ family, $22: 6 \omega_{3}$ (clupanodonic acid) in particular.

In summary, long-chain saturated fatty acids promoted arterial thrombosis tendency in a rat model, whereas certain polyunsaturated fatty acids of the $\omega 6$ and $\omega_{3}$ families had an antithrombotic effect. Monounsaturated fatty acids were neutral in this respect and only decreased arterial thrombosis tendency 'passively' by replacing long-chain saturated fatty acids in the diet.

\section{Effect of dietary lipids on platelet function in rat and man}

Arterial thrombus formation results from platelet reactions and blood coagulation, both initiated and possibly modulated by the vessel wall (Hornstra, 1982). Although the dietary oils rich in linoleic acid or in timnodonic and clupanodonic acids do affect certain aspects of the coagulation system (Hornstra, 1982), these changes seem insufficient to account for the observed antithrombotic effects of such oils. However, it should be realized that measurements performed in systemic blood do not necessarily reflect local processes. Therefore, a role of coagulation in the antithrombotic effect of dietary polyunsaturates cannot be excluded.

The effect of highly-unsaturated oils on platelet aggregation, measured in the traditional way in platelet-rich plasma, also failed to explain the antithrombotic action of these oils (Hornstra, 1982). Since this method will probably not detect differences in blood of certain short-lived substances such as thromboxane $A_{2}$ $\left(\mathrm{TxA}_{2}\right)$ and prostacyclin (prostaglandin $\mathrm{I}_{2}\left(\mathrm{PGI}_{2}\right)$ ), we also used the 'filter-loop technique' (Hornstra, 1970) to investigate the effect of dietary fat on platelet aggregation. This model requires ADP to induce aggregation. However, if a saturated-fat diet had been fed to rats, a reversible 'wave' of spontaneous aggregation would often be observed, the frequency and degree of which was significantly higher than that found when an antithrombotic diet rich in linoleic acid was fed (Hornstra, 1982). In addition, a close correlation was observed between the aggregation tendency of blood platelets and the arterial thrombosis tendency when five different vegetable oils were fed to rats (Fig. 3(a)). These results indicate that the effect of vegetable oils on arterial thrombosis is, at least in part, mediated by their effects on platelet function as measured with the filter-loop technique. This does not seem to apply to marine oils: although whale oil caused the lowest degree of aggregation in this test, arterial thrombosis tendency appeared very high. The reason for this discrepancy is not known and because whale hunting is no longer allowed, it is impossible to investigate this anomaly further. Therefore, we did some studies with cod-liver oil, which revealed another striking 

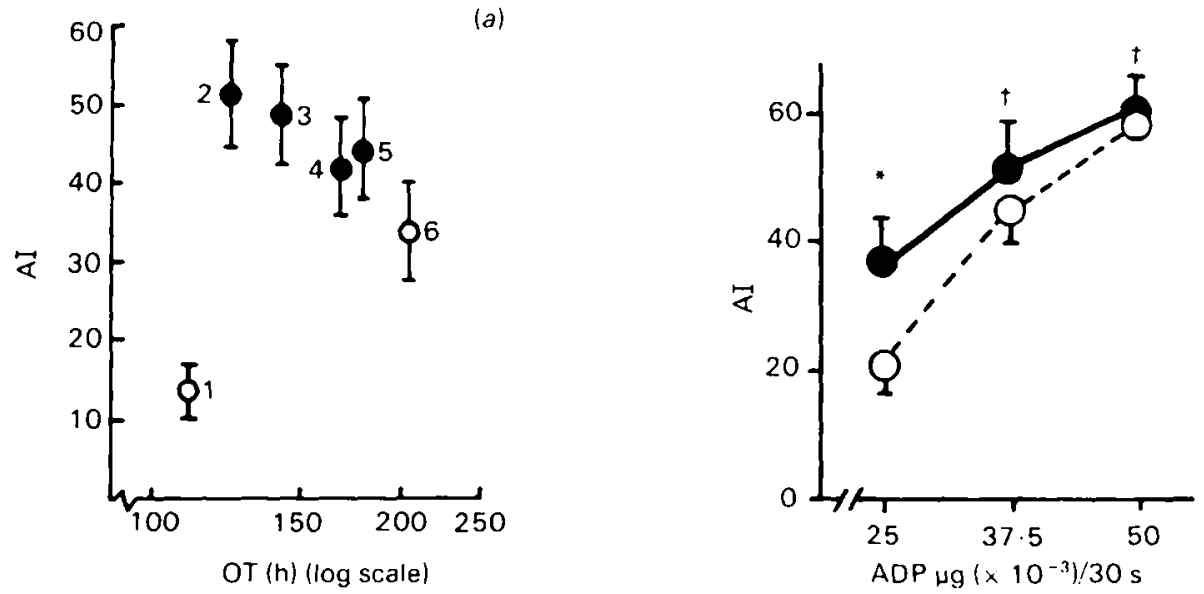

Fig. 3(a). Relation between arterial thrombosis tencincy (obstruction time, OT, h) and ADP-induced aggregation in circulating blood (AI) of rats given diets containing $50 \%$ of digestible energy as different fats for 9 weeks: 1 , whale oil; 2 , soya-bean oil; 3 , hydrogenated soya-bean oil; 4 , sunflower-seed oil; 5 , linseed oil; 6, rapeseed oil. (O), Aggregation significantly different from that in other groups.

(b). Effect of sunflower-seed oil (SO; $50 \%$ of digestible energy; $)$ and cod-liver oil $(45 \%$ of digestible energy $+5 \%$ of digestible energy as $\mathrm{SO} ; \mathrm{O})$, fed for $\mathrm{I} 2$ weeks, on $\mathrm{ADP}$-induced aggregation of platelets in circulating arterial rat blood. Probability of differences (Student's two-sample test): $P_{2}>0 \cdot 1, * P_{2}=0.03$.

In both figures, points are mean values with their standard errors, represented by vertical bars, for twelve rats per group.

discrepancy: although cod-liver oil is at least as antithrombotic as sunflower-seed oil, it caused the ADP-induced aggregation of platelets in circulating arterial blood to increase as compared with sunflower-seed oil (Fig. $3(b)$ ). Most probably, this finding is explained by the lower prostacyclin production in animals given cod-liver oil which is caused by a considerable reduction of the prostacyclin precursor, arachidonic acid, in vascular phospholipids (Hornstra, 1982). These results indicate that, when considering marine oils, ADP-induced platelet aggregation is of limited value to predict an arterial thrombotic risk. For vegetable oils, the predictive power of platelet aggregation seems considerably better, provided aggregation is measured in circulating blood.

Unfortunately, the filter-loop technique for measuring aggregation in circulating blood cannot be used in man. Therefore, we devised a venous modification of the technique, which resulted in the construction of the Filtragometer ${ }^{R}$. Hornstra \& ten Hoor, 1975). This instrument consists of a motor-driven syringe, with which blood from a forearm vein is drawn through a filter. Pressures are measured at both sides of the filter, the pressure difference across the filter being a measure of the amount of aggregates which have been collected on the filter. There is good evidence that the apparatus measures (at least for the greater part) the platelet aggregates present in the blood before it enters the device (Hornstra, 1978). 
Using this instrument, an aggregation study was performed at the end of the 'Helsinki primary prevention trial', conducted by Turpeinen and co-workers in two mental hospitals in the Helsinki region. In one hospital, the normal Finnish diet was given, which is rich in saturated fat and contains only $4 \%$ of the digestible energy (energy \%) as linoleic acid. In the other hospital the diet was modified: milk was replaced by soya-bean-oil-supplemented skim milk, while butter and ordinary margarines were replaced with so-called 'soft' margarines, resulting in a dietary linoleic acid content of 16 energy $\%$. After 6 years, the diets were reversed, the total experimental period being 12 years. The high-linoleic-acid diet was associated with a $50 \%$ reduction in the incidence of coronary heart disease in men but not in women (Miettinen et al. 1972; Turpeinen, 1979; Turpeinen et al. 1979). At the end of the second 6-year period, aggregation was measured in a random sample of the male patients in both hospitals (Hornstra, 1982). These groups were highly comparable as to mean age, body-weight, smoking behaviour and serum triglyceride content. The serum cholesterol content, however, was significantly reduced in the high-linoleic-acid group. Platelet and erythrocyte counts, bleeding time and platelet retention (rotating-bulb technique) were not significantly
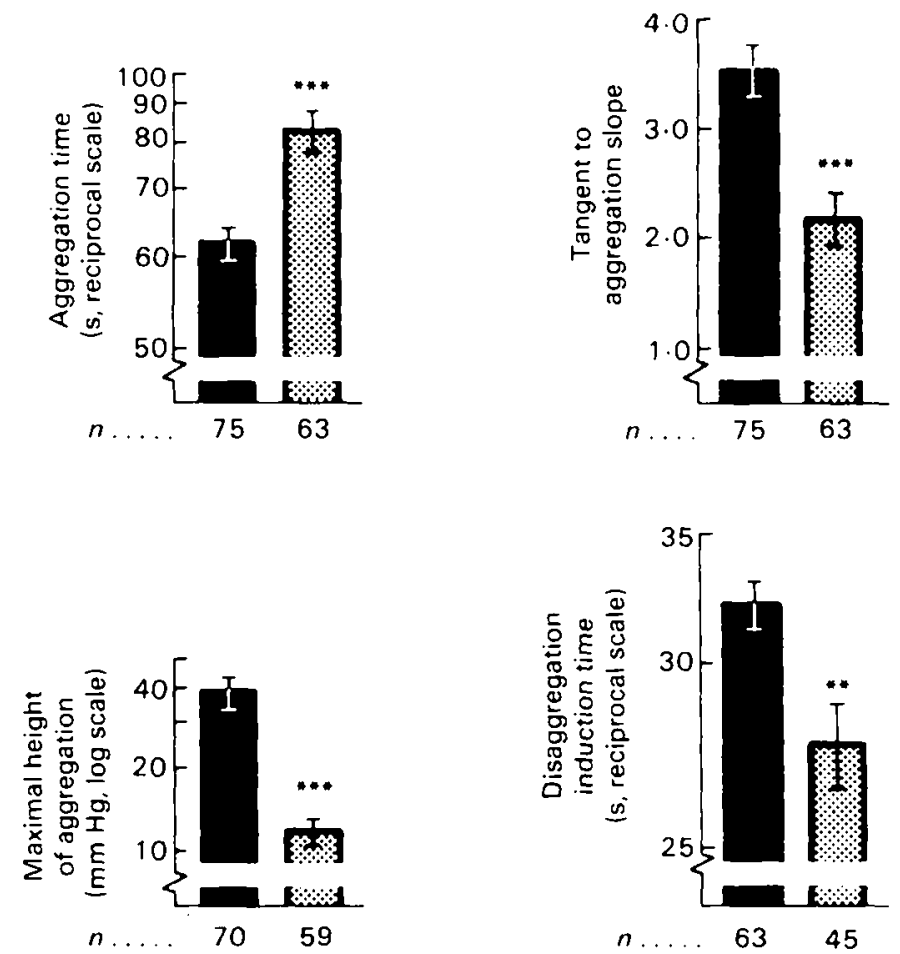

Fig. 4. Effect of dietary linoleic acid content on platelet aggregation (Filtragometer ${ }^{R}$ technique) $^{2}$ in male subjects. Values are means with their standard errors represented by vertical bars. (D), Control diet (4\% of digestible energy as linoleic acid); (), experimental diet (16\% of digestible energy as linoleic acid). Diets had been given for at least 4 years. Probability of difference (Student's two-sample test): ${ }^{\bullet} P_{2}<0.01, \cdots \bullet P_{2}<0.001$. 
different between groups. Platelet aggregation as measured with the Filtragometer, however, appeared greatly reduced in the group receiving the high-linoleic-acid diet (Fig. 4). Although there was a considerable overlap between the groups, mean values for aggregation time, aggregation velocity and maximum aggregation were significantly different. In addition, disaggregation occurred more quickly in the high-linoleic-acid group.

In order to exclude the possibility that the observed differences were caused by other environmental differences between hospitals, aggregation was remeasured 3 months after the dietary linoleic acid content in the experimental hospital had been reduced from 16 to 8 energy \%. This dietary switch caused the aggregation to increase in relation to the values measured in the control hospital, in which the diet did not change (Hornstra, 1982). These findings demonstrate that a high dietary linoleic acid content decreases platelet aggregation as measured with the Filtragometer. Unfortunately, we failed to reproduce these results under short-term (6-week) feeding conditions which is in contrast to results published by others, using the same aggregation methodology (Fleischman et al. 1975a,b).

Whole-blood aggregation has not yet been used to investigate the effect of a fish (oil)-enriched diet on platelet function in man. Such a study is urgently needed, since epidemiological evidence is accumulating that a 'marine diet' lowers mortality from CAD considerably (Hirai et al. 1980; Kronmann \& Green, 1980; Kagawa et al. 1982).

\section{REFERENCES}

Bang, H. O., Dyerberg, J. \& Nielsen, A. (1971). Lancet i, 1143-1146.

Bang, H. O., Dyerberg, J. \& Sinclair, H. M. (1980). American fournal of Clinical Nutrition 33, $2657^{-2661 .}$

Chandler, A. B. (1982). In Dietary Fats, Prostanoids and Arterial Thrombosis, pp. I-14 [G. Hornstra, editor]. The Hague, Boston and London: Martinus Nijhoff Publishers.

Dayton, S., Pearce, M. L., Hashimoto, S. \& Dixon, W. J. (1969). Circulation 40, Suppl. II, 1-63.

Dyerberg, J., Bang, H. O., Stoffersen, E., Moncada, S. \& Vane, J. R. (1978). Lancet ii, i 1 7-1 19.

Fleischman, A. I., Bierenbaum, M. L., Justice, D., Stier, A., Sullivan, A. S. \& Fleischman, M. (1975a). American fournal of Clinical Nutrition 28, 601-605.

Fleischman, A. I., Justice, D., Bierenbaum, M. L., Stier, A. \& Sullivan, A. S. (1975b). Fournal of Nutrition 105, 1286-1 290.

Heyden, S. (1975). In The Role of Fats in Human Nutrition, pp. 43-1 33 [A. J. Vergroesen, editor]. London and New York: Academic Press.

Hirai, A., Hamazaki, T., Terano, T., Nishikawa, T., Tamura, Y., Kumagai, A. \& Sajiki, J. (Ig80) Lancet ii, $1132-1133$.

Hornstra, G. (1970). British fournal of Haemotology 19, $321-329$.

Hornstra, G. (1971). Nutrition and Metabolism 13, 140-149.

Hornstra, G. (1978). In Platelet Function Testing, pp. 416-427 [H. J. Day, H. Holmsen and M. B. Zucker, editors]. US Department of Health, Education and Welfare, Public Health Service, National Institute of Health.

Hornstra, G. (1980). Dietary fats and arterial thrombosis. Thesis, University of Maastricht, The Netherlands.

Hornstra, G. (1982). Dietary Fats, Prostanoids and Arterial Thrombosis. The Hague, Boston and London: Martinus Nijhoff Publishers.

Hornstra, G. \& Lussenburg, R. N. (1975). Atherosclerosis 22, 499-516. 
Hornstra, G. \& ten Hoor, F. (1975). Thrombosis Diathesis Haemorrhagica 34, 53 I-544.

Hornstra, G. \& Vendelmans-Starrenburg, A. (1973). Atherosclerosis 1 7, 369-382.

Kagawa, Y., Nishizawa, M. \& Suzuki, M. (1982). Journal of Nutritional Science and Vitaminology 28, $44 \mathrm{I}-453$.

Kannel, W. B. (1970). In Results of Epidemiologic Investigation of Ischaemic Heart Disease: the Framingham Study, pp. 272-310 [de Haas, Hemker and Snellen, editors]. Leiden: University Press.

Kritchevsky, D. (1969). Annals of the New York Academy of Sciences 162, 80-88.

Kronmann, N. \& Green, A. (1 980). Acta Medica Scandinavica 208, 401-406.

Leren, P. (1970). Circulation 42, 935-942.

Malmros, H. (1969). Lancet ii, 479-484.

Miettinen, M., Turpeinen, O., Karvonen, M. J., Elosuo, R. \& Paavilainen, E. (1972). Lancet ii, $835-838$.

Renaud, S., Morazain, R., McGregor, L. \& Baudier, F. (1979). Haemostasis 8, 234-251.

Stamler, J. (1 973). Medical Clinics of North America 57, 5-46.

Turpeinen, O. (1968). Fournal of the American Dietetic Association 52, 209-2 13.

Turpeinen, O. (1979). Circulation 59, $1-7$.

Turpeinen, O., Karvonen, M., Pekkarinen, M. J., Miettinen, M., Elosuo, R. \& Paavilainen, E. ( 1979 ). International fournal of Epidemiology 8, 99-118.

Vles, R. O., Büller, J., Gottenbos, J. J. \& Thomasson, H. J. (1964). Yournal of Atherosclerosis Research 4, $170-183$.

Weber, G. (1978). In International Conference on Atherosclerosis, pp. I-I 3 [L. A. Carlson, R. Paoletti, C. Sirtori and G. Weber, editors]. New York: Raven Press.

Wissler, R. W. \& Vesselinovitch, D. (1975). Advances in Experimental Medicine and Biology 60, $65-76$. 